\title{
Precise and accurate isotopic analysis of microscopic uranium-oxide grains using LA-MC-ICP-MS
}

\author{
Nicholas S. Lloyd $*^{a}$, Randall R. Parrish ${ }^{a, b}$, Matthew S. A. Horstwood ${ }^{b}$, Simon R. N. Chenery ${ }^{c}$
}

Uranium isotope $\left({ }^{235} \mathrm{U},{ }^{236} \mathrm{U},{ }^{238} \mathrm{U}\right)$ ratios were determined for microscopic uranium-oxide grains using laser-ablation multi-collector inductively-coupled-plasma mass-spectrometry (LA-MC-ICPMS). The grains were retrieved from contaminated soil and dust samples. The analytical technique utilised is rapid, requires minimal sample preparation, and is well suited for nuclear forensic applications. Precision and accuracy were assessed by replicate analyses of natural uraninite grains: relative uncertainty for ${ }^{235} \mathrm{U} /{ }^{238} \mathrm{U}$ is $0.2 \%(2 \sigma)$, and the mean is in agreement with the natural ratio. A total of 115 uranium-oxide grains were analysed from environmental samples (soils and dusts); all of these were depleted uranium (DU) from a factory that produced uranium articles. Knowledge of the range of isotope ratios from particles of this controversial contaminant has proven useful when interpreting isotope ratios from bulk samples. Variation of the measured isotope signatures reveals details of the history of uranium processing and emissions.

\section{Introduction}

Case-study

National Lead Industries (NLI) operated a plant in Colonie (NY, USA), from 1958 - 1984. The plant processed uranium 5 metals (depleted uranium and some enriched uranium); manufacturing kinetic energy penetrators (munitions), counterweights and radiation shielding from depleted uranium (DU). Scrap metal was combusted in a furnace prior to disposal as uranium-oxide, and this resulted in emissions of 10 uranium-oxide particulate to the environment (at times via an unfiltered chimney). ${ }^{1}$ Contamination of the suburban environment surrounding NLI by depleted uranium is evident in air filters, surface soils, reservoir sediments, and the urine of former employees and some residents ${ }^{2-7}$.

15 It is desirable to know the isotope ratios of the contaminant uranium when assessing bulk samples that comprise both background natural uranium and anthropogenic uranium. Furthermore it is possible that the uranium feedstock(s) used at NLI varied in isotopic composition. DU particulates from 20 air filters collected $15.6 \mathrm{~km}$ NNW of NLI in 1979 had variable isotopic composition ${ }^{2}$.

We hypothesise that bulk soil and dust samples aggregate particulates over several decades, and that individual primary uranium-oxide grains from these samples each record the

25 isotopic composition emitted from NLI during a short interval of time.

The bulk environmental samples of interest are contaminated soils (silica-rich medium to fine grained mineral sands with organic matter) and wind-blown dusts, typically comprising 30 up to $500 \mathrm{mg} \mathrm{kg}^{-1}$ anthropogenic uranium, as microscopic uranium-oxide particulate in a matrix of natural mineral grains (that comprise trace natural uranium, less than $2.2 \mathrm{mg} \mathrm{kg}^{-1}$ ). The aim of this study is to analyse the isotopic composition(s) of a population of anthropogenic uranium-oxide grains on an 35 individual particle basis.

Depleted Uranium (DU)

DU is the by-product of nuclear enrichment, and is depleted in the fissile isotope ${ }^{235} \mathrm{U}$, typically $(2-3) \times 10^{-3}{ }^{235} \mathrm{U} /{ }^{238} \mathrm{U}{ }^{8}$. The atom ratio, ${ }^{235} \mathrm{U} /{ }^{238} \mathrm{U}$ (or $n^{235} \mathrm{U} / n^{238} \mathrm{U}$ ), of natural uranium has 40 a traditional consensus value $7.253 \times 10^{-3}(1 / 137.88) 9,10$, recently recommended as $7.257 \times 10^{-3} 11-13$. However, there is evidence of natural isotopic fractionation c. $\pm 0.009 \times 10^{-3}$ of this value ${ }^{14}$, and one known example (Oklo, Gabon) of sustained natural fission resulting in ${ }^{235} \mathrm{U}$ depletion ${ }^{15,16}$.

${ }_{45} \mathrm{~A}$ useful fingerprint of anthropogenic contamination is the presence of ${ }^{236} \mathrm{U}$, which naturally occurs at negligible abundances (in the order of $\times 10^{-11}-\times 10^{-10}{ }^{236} \mathrm{U} /{ }^{238} \mathrm{U}{ }^{17}, 18$ ). In contrast, DU is typically contaminated by up to $3 \times 10^{-5}$ ${ }^{236} \mathrm{U} /{ }^{238} \mathrm{U}$ from reprocessed uranium ${ }^{8} \uparrow$.

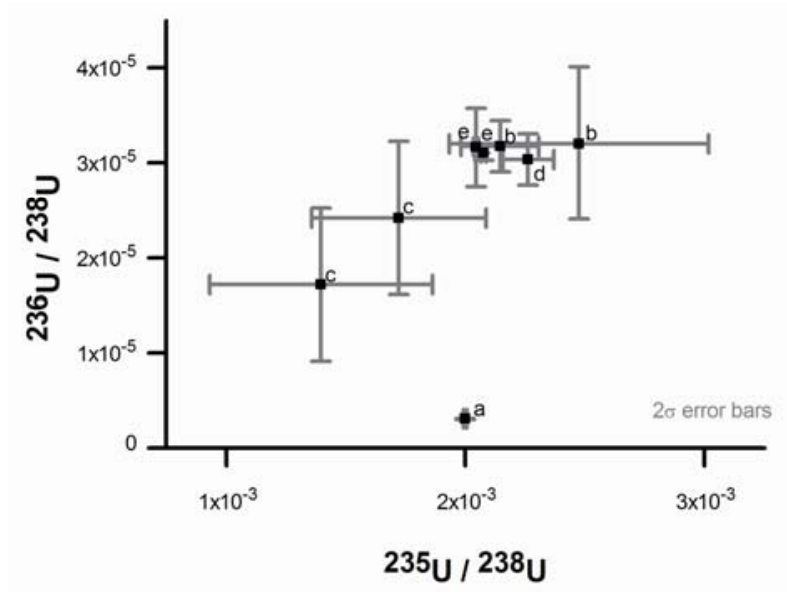

Fig. 1 Isotope ratios of DU penetrators reported in the literature. Measured by gamma-ray spectrometry: a) Trueman et al. (uncertainties from counting statistics only) ${ }^{19}$; alpha spectrometry: b) McLaughlin et al

${ }^{20}$, c) Pöllänen et al ${ }^{21}$, d) Jia et al ${ }^{22}$; ICP-MS: e) Desideri ${ }^{23}$

${ }_{55}$ Figure 1 shows a range of ${ }^{236} \mathrm{U} /{ }^{238} \mathrm{U}$ and ${ }^{235} \mathrm{U} /{ }^{238} \mathrm{U}$ ratios that have been reported in the literature for DU penetrators. There are ranges for both these ratios, but the data are scarce and it is not clear if this reflects a continuously variable range, or discrete batches of DU with distinct isotope signatures. ${ }_{60}$ Furthermore, it is possible that the isotopic compositions of other DU articles are not represented by these data.

Depleted uranium is also depleted in ${ }^{234} \mathrm{U}$; literature values for 
DU munitions range $(0.64-1.1) \times 10^{-5}{ }^{234} \mathrm{U} /{ }^{238} \mathrm{U} \quad{ }^{19-23}$. However, the abundance of this isotope is variable in nature (in the order of $10^{-4}-10^{-5}{ }^{234} \mathrm{U} /{ }^{238} \mathrm{U}$ ) due to alpha recoil effects, and ${ }^{234} \mathrm{U} /{ }^{238} \mathrm{U}$ is not a reliable measure of low-level 5 anthropogenic contamination ${ }^{24,25}$.

Analytical Methods

Radiometric methods of uranium isotopic analysis include alpha and gamma-ray spectrometry. Due to the long half-lives of the uranium isotopes, long counting times (days) are 10 required for precise determination of the minor isotopes. Furthermore, alpha spectrometry requires laborious chemical separation of the analyte from its matrix.

The high-precision analysis of actinide bearing particles by a combination of fission track analysis and thermal ionisation 15 mass spectrometry (FT- TIMS) was described by Dietz ${ }^{2}$, and is the traditional, but laborious method in nuclear forensics ${ }^{26}$. Fission-track analysis is first used to locate actinide-bearing particles for analysis by TIMS. It is also possible to estimate ${ }^{235} \mathrm{U} /{ }^{238} \mathrm{U}$ ratios directly by fission-track analysis ${ }^{27}$. Fission20 track analysis is time consuming and requires access to neutron irradiation facilities. Digital autoradiography ${ }^{28}$ or environmental scanning electron microscopy (SEM) are alternatives for particle location. A disadvantage of TIMS is the requirement for careful chemical separation of the analyte, 25 which may be imperfect and result in poor ionisation and hence precision (risky with only a 'one-shot' analysis per particle).

Inductively-coupled-plasma mass-spectrometry (ICP-MS) offers faster analyses when compared to TIMS, and achieves 30 good precision with multi-collector instruments (MC-ICPMS). However, as for TIMS, particles of interest need to be manipulated and dissolved prior to analysis, and ideally the analyte is chemically separated from its matrix to avoid isobaric interferences. Hydride formation is also an issue ${ }_{35}$ when introducing solution samples, e.g. ${ }^{235} \mathrm{U}^{1} \mathrm{H}$ on ${ }^{236} \mathrm{U}$, but this can be minimised by the use of a desolvating nebuliser.

Secondary ion mass spectrometry (SIMS) has been used in the nuclear forensics context for the precise analysis of uranium and plutonium isotope ratios directly from particulates ${ }^{29-31}$.

${ }_{40}$ SIMS offers excellent spatial resolution, enabling particle location and sub-sampling ${ }^{32}$.

More recently laser ablation ICP-MS (LA-ICP-MS) has been used $^{33-35}$, a method that also requires only minimal sample preparation. Varga ${ }^{36}$ applied LA- sector-field single-collector

${ }_{45}$ ICP-MS (LA-SF-SC-ICP-MS) to non-environmental microscopic grains, demonstrating good agreement with solution SF-SC-ICP-MS, obtaining relative uncertainties $(2 \sigma)$ of c. $5 \%$ for ${ }^{235} \mathrm{U} /{ }^{238} \mathrm{U}$.

Multi-collector (MC-) ICP-MS offers superior isotope ratio 50 measurement precision to ICP-MS and SF-SC-ICP-MS, as the isotope signals are measured simultaneously and generally with higher sensitivity. This is especially important for laser ablation, which produces a variable and transient signal. Boulyga and Prohaska ${ }^{37}$ used a lengthy screening procedure

55 to identify six micro-samples from Chernobyl contaminated soils, for analysis by LA-MC-ICP-MS, obtaining relative uncertainties $(2 \sigma)$ of $2-3 \%$ for ${ }^{235} U /{ }^{238} U$.

The major advantage of both SIMS and LA-ICP-MS is that particles of interest can be selectively sampled directly from 60 solid materials, requiring only minimal sample preparation. However, in practice particles of interest may be very scarce in environmental samples. It is therefore desirable to concentrate these particles prior to analysis, and essential to locate them within the sample mount. The sampling volumes ${ }_{65}$ for both techniques are small, enabling replicate analyses of particles, or analysis by other methods.

The NERC Isotope Geosciences Laboratory (NIGL) are experienced users of LA-MC-ICP-MS for U-Pb dating of zircons (trace uranium decay series) from geological samples.

${ }_{70}$ We have 'borrowed' these sample preparation and analytical techniques for this novel application. To the best of our knowledge, this paper demonstrates for the first time, the application of high precision isotope ratio LA-MC-ICP-MS analysis to a large population of individual uranium-oxide 75 grains from environmental samples.

\section{Experimental}

\section{Sample Preparation}

\section{Samples}

A dust and a surface soil sample were collected from 80 residential properties within $200 \mathrm{~m}$ of the former NLI site. Aliquots of these materials were analysed by scanning electron microscopy with an energy dispersive X-ray analyser (SEM-EDX: Hitachi S-3600N with Oxford Instruments Inca $\mathrm{x}$-sight), revealing discrete uranium-oxide particles. Bulk 85 uranium concentration and isotopic composition were estimated by quadrupole ICP-MS (VG Elemental PQ ExCell with Cetac Technologies Aridus II desolvating nebuliser) after total dissolution: for the soil $90 \pm 9 \mathrm{mg} \mathrm{kg}^{-1}$ uranium, $(2.1 \pm 0.1) \times 10^{-3}{ }^{235} \mathrm{U} /{ }^{238} \mathrm{U}(2 \mathrm{~s})$; and for the dust $385 \pm 33 \mathrm{mg}$ ${ }_{90} \mathrm{~kg}^{-1}$ uranium, $(2.2 \pm 0.1) \times 10^{-3}{ }^{235} \mathrm{U} /{ }^{238} \mathrm{U}$. These isotope ratios confirm that the vast majority of the uranium in these samples is from anthropogenic DU contamination.

Pre-concentration

Table 1 Methodology for concentrating uranium-oxide grains from soil 95 and dust sample, and fractions removed.

\begin{tabular}{|c|c|c|}
\hline process & criteria & fraction removed \\
\hline dry & $60^{\circ} \mathrm{C}$ & moisture \\
\hline sieve & $<250 \mu \mathrm{m}$ & coarse grains \\
\hline hand-magnet & magnetic & magnetite, iron \\
\hline $\begin{array}{l}\text { dense-liquid } \\
\text { (di-iodomethane) }\end{array}$ & $\rho>3.3 \mathrm{~g} \mathrm{~cm}^{-3}$ & $\begin{array}{l}\text { silica and silicates, fine } \\
\text { particulate }\end{array}$ \\
\hline $\begin{array}{l}\text { isodynamic magnetic } \\
\text { separation (Frantz LB-1) }\end{array}$ & $0.1-1 \mathrm{~A}$ & iron-oxides, some zircons \\
\hline sieve & $40 \mu \mathrm{m}$ & coarse and fine fractions \\
\hline
\end{tabular}

The uranium-oxide particulates were concentrated from the bulk samples using the protocol summarized in Table 1. Dense-liquid (di-iodomethane, $\rho 3.3 \mathrm{~g} \mathrm{~cm}^{-3}$ ) was used to 100 separate low-density silicates from the bulk samples, recovering dense grains including uranium-oxides ( $\rho 10.96 \mathrm{~g} \mathrm{~cm}^{-3}$ ) greater than about $20 \mu \mathrm{m}$ diameter.

Grain Mounts

Aliquots of the concentrates were mounted in epoxy resin, 
ensuring separation of grains, and then ground and polished to reveal cross sections (alternatively, they could be adhered whole to the surface of a suitable mount). The mounts were scanned using SEM-EDX to map the uraniferous grains, see 5 Figure 2. Sample preparation and the grain mapping are moderately time consuming. However, the methodology does produce robust grain mounts with a good density of uraniferous grains, which can be quickly located using the laser ablation system's optical microscope.

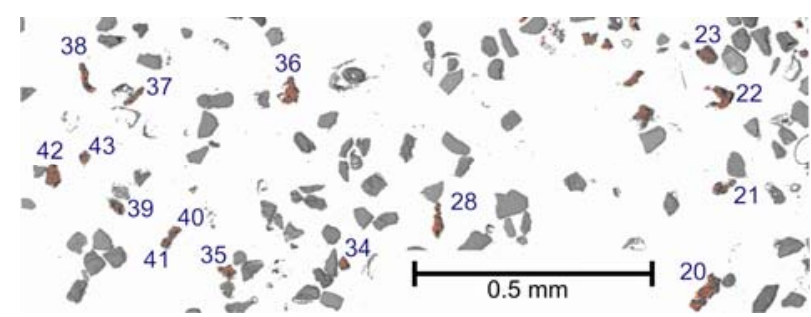

Fig. 2 SEM image of a grain mount surface, overlain by uranium EDX map (highlighting uraniferous grains). Uraniferous grain dimensions for this mount range 12 to $82 \mu \mathrm{m}$, mean $36 \mu \mathrm{m}$.

\section{Solutions}

15 Solutions were prepared from uraniferous grains from these and two other soil dust samples collected from the vicinity of NLI, for comparison with the laser ablation dataset. Spherical grains that appeared metallic or glassy (anthropogenic in appearance) under an optical microscope were picked from 20 the concentrates (under ethanol) using fine tweezers, and then transferred to a low-tack adhesive (Glue Dots Repo ${ }^{\mathrm{TM}}$ ), as shown in Figure 3. These mounts were scanned using SEM-EDX, but fewer than 1 in 40 proved to be uraniferous (the others were mostly lead, tin or lead glass).
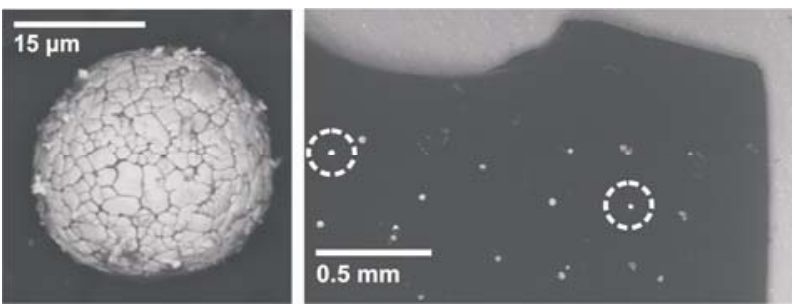

Fig. 3 SEM (uncoated sample, 20 Pa pressure, back scattered electron) image of a typical uranium-oxide sphere, picked from dust concentrate (left). SEM image of a temporary mount, particles with identifiable U M $\alpha$ $\mathrm{X}$-ray peaks from EDX analysis circled (right).

${ }_{30}$ SEM-EDX analyses show the uraniferous grains were typically comprised of only uranium and oxygen (elemental LLD c. $1 \%$ ), for this reason, it was not considered necessary to chemically separate the uranium from these solutions. Subsequent analysis of similar grains shows that they are 35 typically polycrystalline $\mathrm{UO}_{2}$ (unpublished data), and they often include cavities.

Twenty-four uranium-oxide grains were successfully transferred by tweezers into individual pre-leached micro-centrifuge tubes, and then dissolved in ultrapure 40 double-distilled concentrated nitric acid (within a class 100 clean room, typical digest blanks $<100 \mathrm{fg} \mathrm{U}$ ). This method of sample preparation is by comparison with the previous, relatively time-consuming.

\section{Analysis}

45 Mass Spectrometry

Analysis was made using a double-focussing MC-ICP-MS instrument (VG Elemental Axiom), coupled with a desolvating nebuliser (Cetac Technologies Aridus) to reduce hydride interference from solutions. Following peak centring, ${ }_{50}$ low abundance ${ }^{236} \mathrm{U}$ was measured on a secondary electron multiplier, ${ }^{235} \mathrm{U}$ and ${ }^{238} \mathrm{U}$ on Faraday cups. Abundance sensitivity and mass bias were quantified at the start and end of each analytical run, using a natural uranium solution (U950a).

${ }_{55}$ Solutions

The solutions were diluted in ultrapure $2 \% \mathrm{HNO}_{3 \text { (aq) }}$ to approximately $25 \mathrm{ng} \mathrm{g}^{-1}$ uranium. The sample analyses were bracketed by analyses of a solution of enriched uranium standard reference material U010 that includes ${ }^{236} \mathrm{U}$ (New ${ }_{60}$ Brunswick Laboratory).

\section{Laser Ablation of grain mounts}

The grain mounts were sampled by laser-ablation (New Wave Research LUV266x), using a c. $25 \times 14 \mu \mathrm{m}$ spot, $1 \mathrm{~Hz}$ repetition rate at a fluence of c. $68 \mathrm{~mJ} \mathrm{~cm}^{-2}$ (sufficient to give 65 a stable signal within detector range). The output from the desolvating nebuliser provided the carrier-gas flow (c. $11 \mathrm{~min}^{-1} \mathrm{Ar}_{2}$ ) for the ablation cell, and was used for the introduction of solution reference materials U950a and U010 at the start and end of each analytical run.

${ }_{70}$ For each analysis, two baselines were measured at half-mass units (217.5 and 216.5), well away from the masses of interest, to record a good instrument baseline. The laser shutter was opened and the ${ }^{238} \mathrm{U}$ signal monitored until approximately stable, prior to acquisition of 30 one-second 75 integrations. These data were output as the mean and standard error of the mean, after rejection $(10 \%, 2 \sigma)$. The large volume (c. $30 \mathrm{~cm}^{3}$ ) of the ablation cell attenuates the pulses of sample from the ablation, and thereby minimises the effects of the detector response delays between Faraday cups and electron ${ }_{80}$ multiplier. The ${ }^{238} \mathrm{U}$ signal was then monitored for approximately 30 seconds, to allow the passing of 'spikes' from previously ablated material and the return to baseline values, before the next analysis was started.

The ablation protocol used produced irregular conical pits, 85 approximate dimensions $25 \times 14 \times 1 \mu \mathrm{m}$ in uranium-oxide sample grains (measured using SEM and Caminex Enterprises Alicona infinite focus microscope). The sampling volume is roughly equivalent to a $9 \mu \mathrm{m}$ diameter uranium oxide sphere, or 4 ng uranium.

90 Ablation of the resin gave negligible ${ }^{238} \mathrm{U}$ detector responses (c. $3 \times 10^{-5} \mathrm{~V}$ using a $10^{11} \mathrm{ohm}$ resistor, c.f. $1.6 \mathrm{~V}$ from typical samples). Sample grains were bracketed by analyses of natural uraninite grains for quality control. Of the 115 sample grains, 68 were analysed in replicate (up to 21 repeats from a single 95 grain).

\section{Data Processing}

Corrections were made to the data using U950a as a primary reference material: abundance sensitivity $\left({ }^{238} \mathrm{U}\right.$ on ${ }^{236} \mathrm{U}$, 100 c. $\left.1.2 \times 10^{-6}\right)$; hydride for solutions $\left({ }^{238} \mathrm{U}^{1} \mathrm{H} /{ }^{238} \mathrm{U}\right.$ c. $4 \times 10^{-6}$, resulting in ${ }^{235} \mathrm{U}^{1} \mathrm{H} /{ }^{238} \mathrm{U}$ on ${ }^{236} \mathrm{U} /{ }^{238} \mathrm{U}<1 \times 10^{-8}$ ); followed by 
external correction for ${ }^{235} \mathrm{U} /{ }^{238} \mathrm{U}$ instrumental response effects $^{38}$ (approximated by an exponential mass-bias function ${ }^{39}$ ). A secondary reference material, U010, was used to correct for bias between the ion counter and Faraday cups. 5 Estimates of uncertainty were propagated from the analytical standard error of the mean $\left(\sigma_{\mathrm{m}}\right)$ and the relative standard deviations of the corrected primary and secondary reference materials.

\section{Results}

\section{${ }_{10}$ Quality Control}

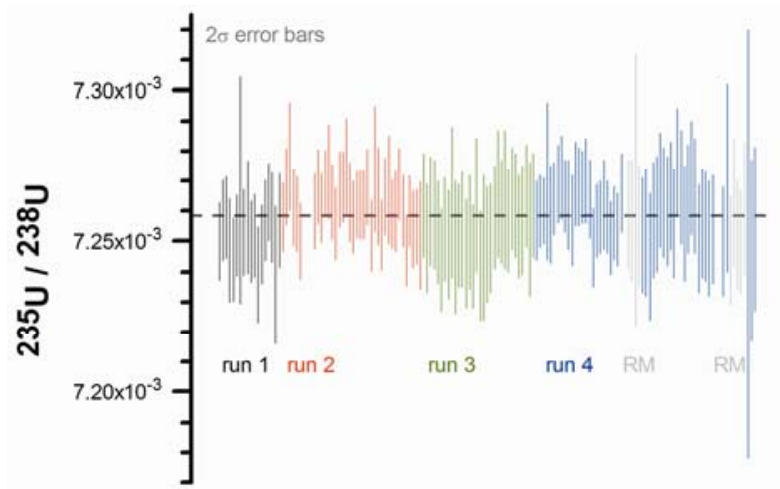

Fig. $4{ }^{235} \mathrm{U} /{ }^{238} \mathrm{U}$ ratios for natural uraninite grains by LA-MC-ICP-MS, from four analytical runs. Nine of the data have been used as reference materials (RM) to correct an observed bias in the second half of run 4 .

15 Natural uraninite grains were ablated 155 times throughout the four analytical runs for quality control. The data are presented in Figure 4 (with 8 outliers removed). Following mid-session calibration, the data in the fourth analytical run drift from a significant low bias. Nine of the uraninite data 20 have been used to bracket the remaining sample and quality control data for that interval (as a tertiary reference material). These self-corrected data are highlighted in Figure 4, and are excluded from the following quality control statistics.

The remaining data $(n=138)$ are normally distributed about an ${ }_{25}$ arithmetic mean ${ }^{235} \mathrm{U} /{ }^{238} \mathrm{U}(7.259 \pm 0.002) \times 10^{-3}\left(2 \sigma_{\mathrm{m}}\right)$. The relative precision for these data is $0.22 \%(2 \sigma)$. The mean is within uncertainty of the recently recommended value ${ }^{12}$, within the range of natural variability ${ }^{14}$, or slightly biased when compared to the traditional consensus 9 .

30 The mean square weighted deviation (MSWD) for these QC data was 1.2 , demonstrating that the propagated uncertainty had probably been slightly underestimated ${ }^{40}$. Therefore, the uncertainties for ${ }^{235} \mathrm{U} /{ }^{238} \mathrm{U}$ have been expanded by $0.1 \%$.

A sample grain (of unknown composition), analysed in 35 replicate during one analytical run ( 2 outliers excluded, $n=21$ ) has an MSWD of 1.6 for ${ }^{235} \mathrm{U} /{ }^{238} \mathrm{U}$; demonstrating that the expanded uncertainties are reasonable. For ${ }^{236} \mathrm{U} /{ }^{238} \mathrm{U}$, an MSWD of 2.6 suggests the uncertainties were underestimated; therefore, they have been expanded by $2 \%$.

40 The relative expanded uncertainties $(2 \sigma)$ for the sample grain data-points, range from $0.2-1.8 \%$ for ${ }^{235} \mathrm{U} /{ }^{238} \mathrm{U}, 2.3-4.0 \%$ for ${ }^{236} \mathrm{U} /{ }^{238} \mathrm{U}$, with medians of 0.4 and $2.7 \%$ respectively. Compared to the uraninite grains, the sample grains have lower ${ }^{235} \mathrm{U} /{ }^{238} \mathrm{U}$, and their ablation is more variable and hence
45 signal, resulting in slightly poorer precisions.

\section{Data}

The analytical data for the laser ablation of uranium-oxide grains are presented in Figure 5A, alongside those from analyses of solutions. The solution data show a similar spread 50 of isotopic compositions to the laser ablation data. All these data are expressed as atom ratios.

Figure 5B shows the data for soils and dusts, and the spread of isotopic compositions from these samples are similar. Particle-solution exchange in the wet soil environment does 55 not explain the spread of data.

\section{Discussion}

\section{Case-study Interpretation}

The data confirm the hypothesis that the individual particles of uranium-oxide record a variety of anthropogenic isotopic 60 compositions, which are averaged in bulk soil and dust samples.

All of the uranium-oxide grains analysed are from DU, with ${ }^{235} \mathrm{U} /{ }^{238} \mathrm{U}$ less than $2.4 \times 10^{-3}$. Enriched uranium grains were not observed; these may be very scarce as comparatively little 65 enriched uranium was handled by NLI, and it may have been recycled because of its value. Enriched uranium was evident in one former employee's urine ${ }^{6}$, implying dispersal of some of this material within the plant and possibly further afield.

NLI reduced uranium tetrafluoride ( $\mathrm{UF}_{4}$, greensalt) feedstock 70 during the $1960 \mathrm{~s}$ and $70 \mathrm{~s}^{1} \ddagger$, these may have been from discrete batches with distinct isotope signatures, or an evolving series of isotopic compositions. A number of processes at NLI could also have mixed these isotopic compositions: feedstock storage, reduction to uranium metal 75 (derby), castings, machining, shop-floor debris, scrap storage, and finally chip burning (conversion) in the furnace releasing uranium-oxide particulates to the environment.

There is a large spread in ${ }^{236} \mathrm{U}$ abundance, with a reasonably well defined mixing-line from $(5-31) \times 10^{-6}{ }^{236} \mathrm{U} /{ }^{238} \mathrm{U}$. These ${ }_{80}$ data range from $(2.05-1.99) \times 10^{-3}{ }^{235} \mathrm{U} /{ }^{238} \mathrm{U}$ with increasing ${ }^{236} \mathrm{U} /{ }^{238} \mathrm{U}$. The data cluster around $2.7 \times 10^{-5}{ }^{236} \mathrm{U} /{ }^{238} \mathrm{U}$, $2.0 \times 10^{-3}{ }^{235} \mathrm{U} /{ }^{238} \mathrm{U}$. We interpret these ratios to follow either a mixing line between two isotopically discrete batches, or an evolving series of compositions. The former hypothesis seems 85 less likely, as there does not appear to be a second cluster.

There is a scatter of ratios up to $5 \times 10^{-5}{ }^{236} \mathrm{U} /{ }^{238} \mathrm{U}$, and up to $2.4 \times 10^{-3}{ }^{235} \mathrm{U} /{ }^{238} \mathrm{U}$. These ratios are explained by inhomogeneous mixing (possibly in the NLI conversion furnace) of a continuation of the previous trend with a third 90 component of slightly less depleted uranium. This hypothesised process also appears to affect some of the grains from the clustered region (Figure Aii), drawing them away from the mixing line. 


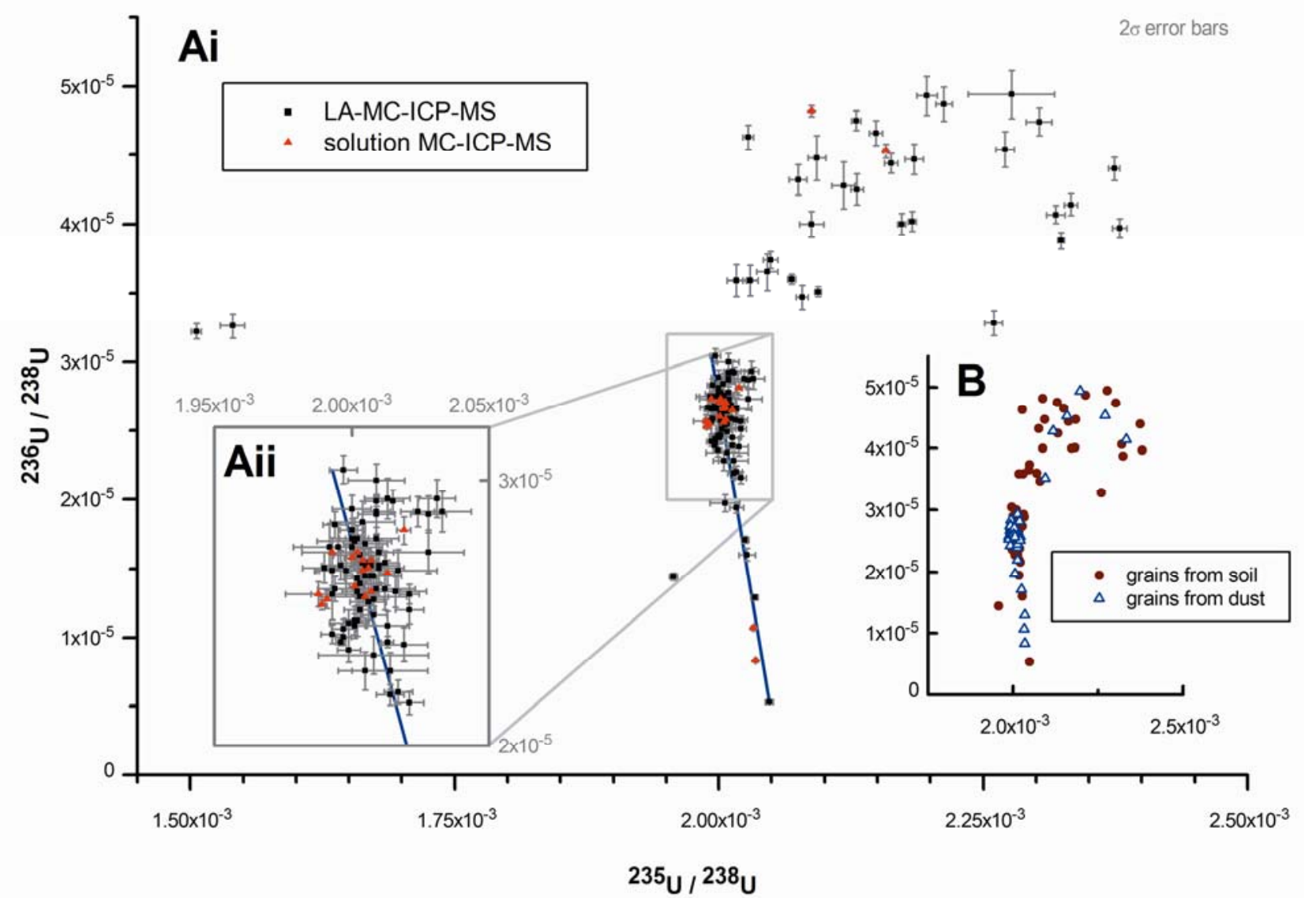

Fig. 5Ai Isotopic compositions from LA- and solution MC-ICP-MS of individual grains. A mixing line passes through the data up to $3 \times 10^{-5}{ }^{236} \mathrm{U} /{ }^{238} \mathrm{U}(\mathrm{Aii}$ 5 expansion of clustered region showing some deviation of, and scatter away from a simple mixing line). B Comparison between analyses of grains from soil and dust samples, showing similar distributions of isotopic compositions.

Two grains have distinct isotope signatures with $(1.5-$ 1.6) $\times 10^{-3}{ }^{235} \mathrm{U} /{ }^{238} \mathrm{U}$, and $(3.2-3.3) \times 10^{-5}{ }^{236} \mathrm{U} /{ }^{238} \mathrm{U}$. The scarcity of these grains suggests that this was a small batch, or 10 that little was released due to improvements in stack filtration.

The isotope signatures revealed by this study are not constrained with respect to age, except for four particles collected by air filters in April and May 1979 and analysed by FT-TIMS ${ }^{2}$ (Figure 6). These ratios fit into the scattered 15 region of out dataset, and support the continuation of the trend of increasing ${ }^{236} \mathrm{U}$ to at least $6 \times 10^{-5}{ }^{236} \mathrm{U} /{ }^{238} \mathrm{U}$. These are most likely to have been from emissions at that time. However, the scrap metal may have accumulated for several months before conversion. The isotopic compositions of the uranium 20 materials processed by NLI appear to have been more variable during this period.

It was reported that in 1980, 150 drums of waste uranium had accumulated over several months, and nearly 2 tonnes were converted to oxide in March and April of that year, with the 25 release of only $7.5 \mathrm{~g}$ of uranium, thanks to operation of, and improvements to a filtration system, following enforcement action ${ }^{41}$. Extensive uranium contamination of soils is evident by $1980^{3}$, estimated in the order of 5 tonnes uranium deposited on soils within $1 \mathrm{~km}^{2}{ }^{6}$. The vast majority of the 30 contamination from NLI pre-dates 1980 , therefore the sample grains analysed in this study probably also pre-date 1980 . Based on the number of grains loosely tied to 1979 (c. 20\%), a significant portion of the contamination appears to have been emitted during that period.

${ }_{35}$ We speculate that the feedstock received by NLI evolved through a series of compositions, from $2.05 \times 10^{-3}{ }^{235} \mathrm{U} /{ }^{238} \mathrm{U}$ with minor ${ }^{236} \mathrm{U}$ contamination $\left(<5 \times 10^{-6}{ }^{236} \mathrm{U} /{ }^{238} \mathrm{U}\right)$, to $1.99 \times 10^{-3}{ }^{235} \mathrm{U} /{ }^{238} \mathrm{U}$ with $3 \times 10^{-5}{ }^{236} \mathrm{U} /{ }^{238} \mathrm{U}$. Subsequently, and by 1979 , the primary NLI feedstock evolved to at least $6 \times 10^{-5}$ ${ }_{40}^{236} \mathrm{U} /{ }^{238} \mathrm{U}$, but during that time 'less depleted' uranium was also used. Continued depletion at the gaseous diffusion plant of uranium comprising $2 \times 10^{-3}{ }^{235} \mathrm{U} /{ }^{238} \mathrm{U}, 4 \times 10^{-5}{ }^{236} \mathrm{U} /{ }^{238} \mathrm{U}$ could result in the isotope ratios of the most depleted uranium-oxide grains analysed. These interpretations are 45 summarised in Figure 6.

A chronology for these data could be established using ${ }^{230} \mathrm{Th} /{ }^{234} \mathrm{U}, \quad{ }^{231} \mathrm{~Pa} /{ }^{235} \mathrm{U}$ or possibly ${ }^{232} \mathrm{Th} /{ }^{236} \mathrm{U}$ dating of particles. The measurements would be technically challenging; with daughter radionuclides in the sub50 femtogram range per grain (and are dependent on initial uranium separation). Uranium dating by ${ }^{230} \mathrm{Th} /{ }^{234} \mathrm{U}$ using ICPMS has been successfully demonstrated by Varga and Surányi ${ }^{42}$, but improvements in sensitivity would be required for the dating of individual grains. 


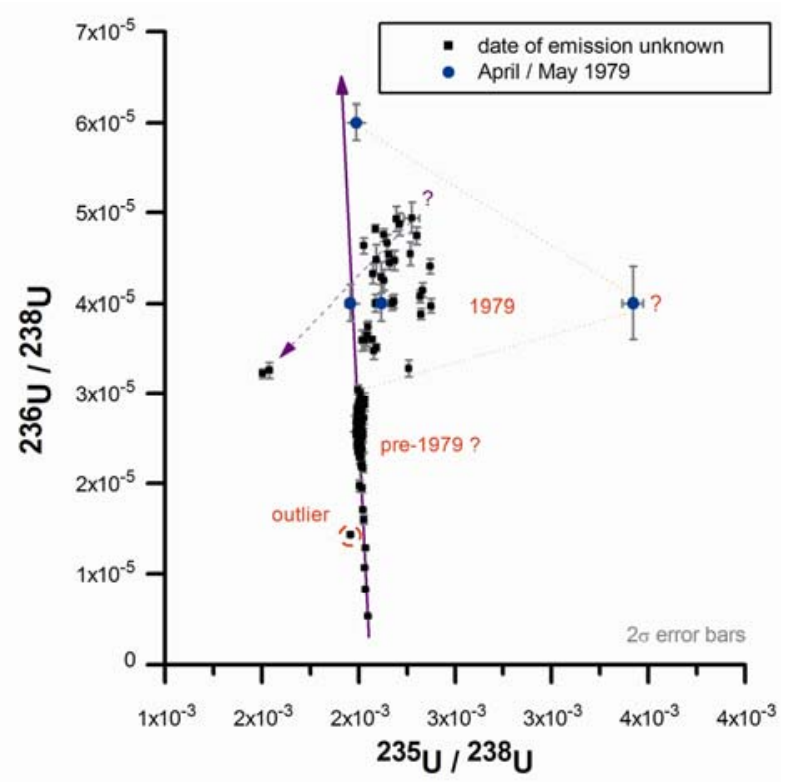

Fig. 6 Speculative explanation of the isotope ratios measured for this case-study. The solid arrow shows the primary NLI feedstock evolving with increasing ${ }^{236} \mathrm{U}$ contamination. A possible secondary feedstock 5 follows the dashed arrow with increasing ${ }^{235} \mathrm{U}$ depletion at the gaseous diffusion plant, leading to the most depleted grains. A scatter of isotopic compositions within the dotted triangular region can be explained by inhomogeneous mixing with 'less depleted' uranium batch(es). The timing is loosely tied by four particles collected by air filters in April and $10 \quad$ May $1979^{2}$. A larger dataset could resolve these details.

The spread of ${ }^{235} \mathrm{U} /{ }^{238} \mathrm{U}$ isotope ratios revealed by this study is matched by those in Figure 1, but we are able to resolve more information from this large and precise dataset. Some of these DU grains comprise more ${ }^{236} \mathrm{U}$ than previously reported.

15 These data show that at least some of the DU processed at NLI had low levels of ${ }^{236} \mathrm{U}$. Therefore, ${ }^{236} \mathrm{U}$ cannot be used as a defining fingerprint of DU contamination if, as for quadrupole ICP-MS, the lower limit of detection of the analytical technique approaches these ratios.

20 Analytical Methodology

Laser ablation allows for the rapid collection of data, when compared to TIMS or solution ICP-MS. A typical sample grain analysis took less than two minutes, and the instrumental productivity (including set-up, reference 25 materials, and particle location), was around 16 minutes per sample grain. Modern MC-ICP-MS systems offer faster set-up times, which could further improve productivity.

Pre-concentration of particles of interest using dense liquid separation was quick and effective, and allows for efficient 30 analysis by laser ablation (or SIMS). However, the methodology does bias the sample by excluding particulates and grains smaller than approximately $20 \mu \mathrm{m}$. Smaller grains could be recovered using heavy-liquids with centrifugation ${ }^{43}$, froth-floatation ${ }^{44}$, or inertial separation. Alternatively raw 35 samples may be analysed, but requiring more time searching for the grains of interest and exchanging sample mounts. It is not necessary to embed and polish the particles; they could be adhered to a mount with a clean adhesive, or sampled directly from a swipe sample.

40 The volume of sample consumed per analysis is small when compared to the volume of the grains of interest, and allows for replicate analyses. The sampling area is similar to the extent of the grains presented on the mount surface. Smaller particles can be analysed, when sufficiently separated from 45 each other, as the uranium content of the resin is indistinguishable from detector noise. However, there is potential for minor additional ${ }^{235} \mathrm{U}^{1} \mathrm{H}$ formation with hydrogen liberated from the epoxy resin. Clean mounting material would be necessary for fine particulates, for example carbon 50 planchets. Modern laser systems can also achieve better spatial resolution.

An observed bias in the quality control data for part of one analytical run was corrected by using some of these data as a tertiary standard. There are variations in the uraninite data, 55 and the uncertainties were slightly underestimated, both of which can also be explained by changes in instrument bias between external corrections. This demonstrates the need for more frequent monitoring, preferably by laser ablation of a solid reference material that includes ${ }^{236} \mathrm{U}$ (e.g. New ${ }_{60}$ Brunswick Laboratory U005-A). These minor issues were not significant to our interpretations of the sample data.

Accuracy was demonstrated by repeat analyses of natural uraninite grains; the mean value agrees with the "natural ratio'. Relative precision over four analytical runs of $0.2 \%$ ${ }_{65}(2 \sigma)$ for ${ }^{235} \mathrm{U} /{ }^{238} \mathrm{U}$ is better or at least comparable to the current methodologies used for nuclear forensic applications. Relative uncertainties $(2 \sigma)$ for the sample grains ranged between $0.2-1.8 \%$ for ${ }^{235} \mathrm{U} /{ }^{238} \mathrm{U}$, and $2.3-4.0 \%$ for ${ }^{236} \mathrm{U} /{ }^{238} \mathrm{U}$. The precision of this method was more than 70 adequate to resolve differences in the isotopic composition of microscopic grains of DU-oxide.

The precision of LA-MC-ICP-MS compares favourably with LA-SF-SC-ICP-MS ${ }^{36}$, and is similar for SIMS analyses of particles from environmental samples ${ }^{29,31}$. It is hard to judge 75 from the literature that achieved by FT-TIMS, although TIMS may offer better analytical precision. However, our method allows the acquisition of large datasets that may be more representative of the samples, the precision is fit-for-purpose, and appears to be a significant way forward for nuclear ${ }_{80}$ forensics. For this case-study, a larger dataset could resolve further details regarding the history of uranium processing at NLI (perhaps twice as large, and including sample from other locations for representativity).

\section{Conclusions}

${ }_{85}$ We have demonstrated the use of LA-MC-ICP-MS to rapidly analyse a large population of microscopic uranium-oxide grains for an environmental case-study. It is clear from these and other data that the isotopic compositions of depleted uranium are variable, especially with respect to ${ }^{236} \mathrm{U}$.

${ }_{90}$ The accuracy and precision analysing ${ }^{235} \mathrm{U} /{ }^{238} \mathrm{U}$ for natural uranium was excellent. Typical relative uncertainties $(2 \sigma)$ of $0.4 \%$ for ${ }^{235} \mathrm{U} /{ }^{238} \mathrm{U}$ and $2.7 \%$ for ${ }^{236} \mathrm{U} /{ }^{238} \mathrm{U}$, are well-suited to nuclear forensic applications, and are an improvement over single-collector (quadrupole or sector-field) LA-ICP-MS. LA${ }_{95}$ MC-ICP-MS offers several advantages to nuclear forensics, including fast analysis time, minimal sample preparation, and partial ablation of the sample. 


\section{Acknowledgements}

This study is sponsored by the British Geological Survey and the NERC Isotope Geosciences Laboratory. The authors would like to thank Tim S. Brewer ${ }^{\text {RIP }}$, Mark A. Purnell ${ }^{\mathrm{a}}$, 5 Jennifer M. Bearcock ${ }^{c}$, Adrian K. Wood ${ }^{b}$ and John G. Arnason for their assistance.

In memoriam Leonard A. Dietz: an inspiration to this study as a pioneer of early TIMS and electron multiplier technologies. He highlighted the contamination of the environment by NLI 10 in 1979, and latterly campaigned against DU munitions.

This paper is published with the permission of the Director of the British Geological Survey.

\section{Notes and References}

${ }^{a}$ University of Leicester, Department of Geology, University Road, 15 Leicester, LE17RH, UK.E-mail:nsl3@le.ac.uk

${ }^{b}$ NERC Isotope Geosciences Laboratory, Kingsley Dunham Centre, Keyworth, Nottingham, NG12 5GG, UK. E-mail: rrp@bgs.ac.uk, msah@bgs.ac.uk

${ }^{c}$ British Geological Survey, Kingsley Dunham Centre, Keyworth, 20 Nottingham, NG12 5GG, UK. E-mail: srch@bgs.ac.uk

Sample data are available from the RSC's Electronic Supplementary Information (ESI) service at: www.rsc.org/XXXXX.

$\dagger$ The source of ${ }^{236} U$ contamination is from reprocessed uranium (neutron capture on ${ }^{235} \mathrm{U}$ in nuclear power or production reactors). Reprocessed

25 uranium can comprise up to $0.5 \%{ }^{236} \mathrm{U}^{26}$, typically $0.4-0.6 \%{ }^{236} \mathrm{U}^{45}$, which when enriched would produce by-product DU in the order of a part per thousand ${ }^{236} \mathrm{U}$, with ${ }^{236} \mathrm{U}$ concentrated in the enriched uranium. For DU with $3 \times 10^{-5}{ }^{236} \mathrm{U}$, the source of ${ }^{236} \mathrm{U}$ is either cross-contamination via enrichment-plant machinery, or blending of virgin uranium with 30 reprocessed uranium, on the order of a percent reprocessed uranium. Presumably the level of contamination depends on the nuclear enrichment facilities' history of handling reprocessed uranium. Civilian uranium reprocessing in the USA ceased in $1977^{45}$, therefore the abundance of ${ }^{236} \mathrm{U}$ in recently produced DU is likely to be lower.

$35 \div$ It is not clear where the DU feedstock for NLI was sourced. A DoE press release ${ }^{46}$ identifies 11 US sites that handled reprocessed uranium, including 3 gaseous diffusion enrichment plants (Oak Ridge, TN; Puducah, KY; Portsmouth, $\mathrm{OH}$ ) and 1 uranium hexafluoride reduction facility (Fernald, $\mathrm{OH}$ ). If Fernald produced the $\mathrm{UF}_{4}$ for NLI, it seems 40 likely that the $\mathrm{UF}_{6}$ was supplied from neighbouring Portsmouth.

1. ATSDR, Health Consultation: Colonie Site, Agency for Toxic Substances and Disease Registry, Atlanta, USA, 2004.

2. L. A. Dietz, Investigation of Excess Alpha Activity Observed in 45 Recent Air Filter Collections and Other Environmental Samples, Letter CHEM-434-LAD, Knolls Atomic Power Laboratory, General Electric Company, Schenectady, NY, USA, 1980.

3. H. W. Jeter and D. M. Eagleson, A survey of uranium in soils surrounding the NL Bearings Plant, Report IWL-9488-461, Teledyne Isotopes, Westwood, NJ, 1980.

4. J. G. Arnason and B. A. Fletcher, Environ. Pollut., 2003, 123, 383391.

5. D. Lo, R. L. Fleischer, E. A. Albert and J. G. Arnason, J. Environ. Radioact., 2006, 89, 240-248.

55 6. R. R. Parrish, M. Horstwood, J. G. Arnason, S. Chenery, T. Brewer, N. S. Lloyd and D. O. Carpenter, Sci. Total Environ., 2008, 390, 5868.

7. N. S. Lloyd, R. R. Parrish, S. R. Chenery and J. G. Arnason, Geochim. Cosmochim. Acta, 2008, 72, A566.

60 8. A. Bleise, P. R. Danesi and W. Burkart, J. Environ. Radioact., 2003, 64, 93-112.

9. R. H. Steiger and E. Jäger, Earth Planet. Sci. Lett., 1977, 36, 359362.

10. K. J. R. Rosman and P. D. P. Taylor, J. Phys. Chem. Ref. Data, 1998, $65 \quad 27,1275-1287$
11. S. Richter, A. Alonso, W. De Bolle, R. Wellum and P. D. P. Taylor, Int. J. Mass Spectrom., 1999, 193, 9-14.

12. J. R. De Laeter, J. K. Böhlke, P. De Bièvre, H. Hidaka, H. S. Peiser, K. J. R. Rosman and P. D. P. Taylor, Pure Appl. Chem., 2003, 75, 683-800

13. S. Richter, A. Alonso-Munoz, R. Eykens, U. Jacobsson, H. Kuehn, A. Verbruggen, Y. Aregbe, R. Wellum and E. Keegan, Int. J. Mass Spectrom., 2008, 269, 145-148.

14. S. Weyer, A. D. Anbar, A. Gerdes, G. W. Gordon, T. J. Algeo and E. A. Boyle, Geochim. Cosmochim. Acta, 2008, 72, 345-359.

15. R. Bodu, H. Bouzigues, N. Morin and J. P. Pfiffelmann, C. $R$ Seances Acad. Sci., Ser. D, 1972, 275, 1731-1732.

16. M. Neuilly, J. Bussac, C. Frèjacques, G. Nief, G. Vendryes and J. Yvon, C. R. Seances Acad. Sci., Ser. D, 1972, 275, 18471849.

80 17. X. L. Zhao, M. J. Nadeau, L. R. Kilius and A. E. Litherland, Nucl. Instrum. Methods Phys. Res., Sect. B, 1994, 92, 249-253.

18. D. Berkovits, H. Feldstein, S. Ghelberg, A. Hershkowitz, E. Navon and M. Paul, Nucl. Instrum. Methods Phys. Res., Sect. B, 2000, 172, 372-376.

85 19. E. R. Trueman, S. Black and D. Read, Sci. Total Environ., 2004, 327, 337-340.

20. J. P. McLaughlin, L. L. Vintro, K. J. Smith, P. I. Mitchell and Z. S. Zunic, J. Environ. Radioact., 2003, 64, 155-165.

21. R. Pöllänen, T. K. Ikäheimonen, S. Klemola, V.-P. Vartti, K. Vesterbacka, S. Ristonmaa, T. Honkamaa, P. Sipilä, I. Jokelainen, A. Kosunen, R. Zilliacus, M. Kettunen and M. Hokkanen, J. Environ. Radioact., 2003, 64, 133-142.

22. G. Jia, M. Belli, U. Sansone, S. Rosamilia and S. Gaudino, J. Radioanal. Nucl. Chem., 2004, 260, 481-494.

95 23. D. Desideri, M. A. Meli, C. Roselli, C. Testa, S. F. Boulyga and J. S. Becker, Anal. Bioanal. Chem., 2002, 374, 1091-1095.

24. R. L. Fleischer, Geochim. Cosmochim. Acta, 1982, 46, 2191-2201.

25. R. L. Fleischer, Health Phys., 2008, 94, 292-293.

26. D. L. Donohue, J. Alloys Compd., 1998, 271-273, 11-18.

100 27. O. Stetzer, M. Betti, J. Van Geel, N. Erdmann, J. V. Kratz, R. Schenkel and N. Trautmann, Nucl. Instrum. Methods Phys. Res., Sect. A, 2004, 525, 582-592.

28. C. J. Zeissler, Nucl. Instrum. Methods Phys. Res., Sect. A, 1997, 392, 249-253.

105 29. M. Betti, G. Tamborini and L. Koch, Anal. Chem., 1999, 71, 26162622.

30. G. Tamborini, Microchim. Acta, 2004, 145, 237-242.

31. F. Esaka, M. Magara, C. G. Lee, S. Sakurai, S. Usuda and N. Shinohara, Talanta, 2009, 78, 290-294.

110 32. X. Hou, W. Chen, Y. He and B. T. Jones, Applied Spectroscopy Reviews, 2005, 40, 245-267.

33. J. S. Becker, Int. J. Mass Spectrom., 2005, 242, 183-195.

34. Z. Stefánka, R. Katona and Z. Varga, J. Anal. At. Spectrom., 2008, 23, 1030-1033.

115 35. J. S. Becker, H. Sela, J. Dobrowolska, M. Zoriy and J. S. Becker, Int. J. Mass Spectrom., 2008, 270, 1-7.

36. Z. Varga, Anal. Chim. Acta, 2008, 625, 1-7.

37. S. F. Boulyga and T. Prohaska, Anal. Bioanal. Chem., 2008, 390 , 531-539.

120 38. C. P. Ingle, B. L. Sharp, M. S. A. Horstwood, R. R. Parrish and D. J. Lewis, J. Anal. At. Spectrom., 2003, 18, 219-229.

39. W. A. Russell, D. A. Papanastassiou and T. A. Tombrello, Geochim. Cosmochim. Acta, 1978, 42, 1075-1090.

40. I. Wendt and C. Carl, Chem. Geol., 1991, 86, 275-285.

125 41. D. J. Romano, in Governor's Task Force on NL, N.Y.S. Department of Environmental Conservation, Albany, NY, USA, 1982.

42. Z. Varga and G. Surányi, Anal. Chim. Acta, 2007, 599, 16-23.

43. K. J. Henley, Am. Mineral., 1977, 62, 377-381.

44. US Pat., 4830738, 1989.

130 45. World Nuclear Association, Processing of Used Nuclear Fuel for Recycle http://www.world-nuclear.org/info/inf69.html, Accessed 02/09/2008.

46. DoE, Past Recycled Uranium Programs Under Review as Energy Department Investigation Continues, http://www.ne.doe.gov/home/929-99.html, Accessed 02/09/2008. 